We are grateful to $\mathrm{Dr} J \mathrm{~S}$ Fleming and $\mathrm{Mr} \mathrm{G} \mathrm{H}$ Smith for permission to report details of this patient, who was under their care. One of us $(C W)$ is in receipt of a British Heart Foundation research grant (No 496).

${ }^{1}$ Levison, D A, et al, Lancet, 1971, 2, 844.

2 Birkhead, J S, and Apostolov, K, British Heart fournal, 1974, 36, 728.

${ }^{3}$ Meyer, K F, in Viral and Rickettsial Infections of Man, ed F L Horsfall and I Tamm, 4th edn. London, Pitman Medical, 1965.

Cardiothoracic Unit and Department of Pathology, Northern General Hospital, Sheffield 5

C WARD, MD, MRCP, senior registrar

H J SAGAR, BM, MRCP, senior house officer

D COOPER, MB, MRCPATH, senior registrar

Department of Immunology, Hallamshire Hospital, Sheffield 10 A MILFORD WARD, MB, MRCPATH, consultant in charge

\section{Plasma free fatty acid levels in acute myocardial infarction in diabetic and non-diabetic patients}

Acute myocardial infarction carries a high mortality among patients suffering from diabetes mellitus and there is a suggestion that the risk of cardiovascular death may be increased by the use of hypoglycaemic drugs ${ }^{1}$. A high incidence of primary ventricular fibrillation among those previously on oral hypoglycaemic drugs has also been found ${ }^{2}$.

As raised plasma free fatty acids (FFA) have been implicated in the genesis of cardiac arrhythmias ${ }^{3}$, we considered that this may be the mechanism in diabetics, who are known to have impairment of the normal fall in FFA levels after glucose ingestion after myocardial infarction ${ }^{4}$.

We therefore decided to investigate the relation between the incidence of ventricular fibrillation among diabetic patients admitted with acute myocardial infarction and the levels of circulating FFA and to compare the findings with those observed in non-diabetic people.

\section{Patients, methods, and results}

Twenty-three diabetic and 24 non-diabetic patients with proved myocardial infarction within the previous 30 hours were studied. Twelve of the diabetics were women whereas there were only two women among the non-diabetics. The mean age of the diabetic patients was significantly higher than that of the non-diabetics, but the ages of the orally treated and insulintreated diabetics were similar. The insulin-treated group had had diabetes longer than the tablet-treated patients ( 15 years and 6.1 years respectively.) A venous blood sample was taken from each patient on admission, which was a mean of 6.57 hours after the onset of chest pain in the non-diabetic patients and 9.9 hours in the diabetics. The plasma sugar was measured and FFA levels estimated using a modification of the method of Dole and Meinertz, ${ }^{5}$ substituting tetra-n-butyl ammonium hydroxide as titrant. Serum albumin was also measured within 24 hours.

Initial plasma sugar concentrations were significantly higher among the diabetic than among the non-diabetic patients $(P<0.0005)$, but no difference emerged between the two groups in FFA levels. There was also no significant difference in circulating FFA between those patients on oral drug treatment and those receiving insulin. Ten patients, five in each group, developed primary ventricular fibrillation. No difference was detected in the corresponding FFA levels between patients who developed this arrhythmia and those who did not, either when the results were analysed as a whole or when the diabetics were considered separately. In eight of these 10 patients, the blood sample was taken within one and a half hours of the occurence of the arrhythmia.

Nine of the 47 patients died in hospital. Seven of these were diabetics, of whom five were on insulin. Serum albumin was lower in the diabetics than in the non-diabetics $(P<0.01)$. Three newly diagnosed diabetics and three on diet alone were included in the study. They had an uncomplicated progress.

\section{Discussion}

The diabetic population showed the high proportion of women and high overall mortality previously noted ${ }^{2}$. The raised blood sugar in the diabetic group was evidence of lack of control of diabetes. FFA levels in diabetic and non-diabetic patients, however, did not differ significantly. Also, levels of FFA in those patients developing ventricular fibrillation were similar to those in patients who did not. Serum albumin was lower in the diabetics who might have produced more unbound FFA, which in turn might have exerted a greater effect on the myocardium, but this was not borne out by the similar FFA levels in the diabetics with and without ventricular fibrillation. The numbers in this comparison were, however, smaller. Thus, although the mean values for circulating FFA were above the threshold levels of $1.2 \mathrm{mmol} / \mathrm{l}^{3}$, the concentrations of plasma FFA did not correlate with the development of ventricular fibrillation.

We thank Sisters P Lamb and A Rees-Jones of the cardiac care unit of the General Hospital for their help.

1 University Group Diabetes Program, Diabetes, 1970, 19, Suppl 2, p 747.

2 Soler N G, et al, Quarterly fournal of Medicine, 1975 44, 125.

3 Oliver, M F Kurien, V A, and Greenwood, T W, Lancet, 1968, 1, 710.

4 Soloff, L A, and Schwartz, H, Lancet, 1966, 1, 449.

5 Dole, V P, and Meinertz, H, fournal of Biological Chemistry, 1960, 235, 2595

General Hospital, Birmingham B4 6NH

C A SYKES, MB, MRCP, United Birmingham Hospitals Endowment Fund research fellow.

A D WRIGHT, MB, FRCP(C), senior lecturer

J M MALINS, MD, FRCP, consultant physician

B L PENTECOST, MD, FRCP, consultant physician

Department of Experimental Pathology, University of Birmingham, Birmingham

RODNEY WATTS, PHD, research fellow

\section{Circulating thyroid hormone concentrations and posture and venous compression}

An increase in hydrostatic pressure produced by a change in posture to the upright position or application of a venous tourniquet causes a transudation of protein-free solute from the circulation with a resultant rise in plasma protein concentration. ${ }^{12}$ Circulating thyroid hormones are almost totally bound to serum protein and it is known

Mean ( $\pm 1 S D$ ) plasma FFA levels on initial blood sample after admission and in relation to ventricular fibrillation (VF) together with mean ( \pm 1 SD) plasma sugar and serum albumin concentrations

\begin{tabular}{|c|c|c|c|c|c|c|c|c|}
\hline & $\begin{array}{c}\text { Non-diabetics } \\
(n=24)\end{array}$ & $\begin{array}{l}\text { Diabetics } \\
(\mathbf{n}=23)\end{array}$ & $\begin{array}{c}\text { Diabetics on } \\
\text { oral drugs } \\
(n=8)\end{array}$ & $\begin{array}{l}\text { Diabetics on } \\
\text { insulin } \\
(n=9)\end{array}$ & $\begin{array}{l}\text { All patients } \\
\text { with VF } \\
(\mathbf{n}=10)\end{array}$ & $\begin{array}{l}\text { All patients } \\
\text { without VF } \\
(\mathrm{n}=37)\end{array}$ & $\begin{array}{l}\text { Diabetics } \\
\text { with VF } \\
(\mathbf{n}=5)\end{array}$ & $\begin{array}{c}\text { Diabetics } \\
\text { without VF } \\
(n=18)\end{array}$ \\
\hline $\begin{array}{l}\text { Plasma FFA (mmol/l) } \\
\text { Plasma sugar }(\mathrm{mmol} / \mathrm{l}) \\
\text { Serum albumin }(\mathrm{g} / \mathrm{l})\end{array}$ & $\begin{aligned} 1.35 & \pm 0.46 \\
7.7 & \pm 1.6 \\
42.0 & \pm 3.1\end{aligned}$ & $\begin{array}{l}1.42 \pm 0.60 \\
16.0 \pm 7.8 \\
39.0 \pm 4.1\end{array}$ & $\begin{array}{l}1.56 \pm 0.69 \\
17 \cdot 0 \pm 8.7 \\
37.4 \pm 4.4\end{array}$ & $\begin{array}{l}1.40 \pm 0.56 \\
16.6 \pm 8 \cdot 1 \\
39.8 \pm 3.5\end{array}$ & $1.53 \pm 0.60$ & $1.35 \pm 0.51$ & $1.30 \pm 0.59$ & $1.46 \pm 0.62$ \\
\hline
\end{tabular}


that venous compression by arm tourniquet for five minutes may increase protein-bound iodine by $22.4 \% \mathrm{~s}^{3}$

The present study was designed to test the effects of postural change and venous compression on the serum concentrations of thyroxine (T4) and triiodothyronine (T3).

\section{Patients, methods, and results}

Three studies were performed on 19 nonfasted normal subjects. No subject was oedematous or had any abnormality of hepatic, renal, or thyroid function. Blood was taken without hand squeezing. In the first study, to test the effect of posture, blood was taken without a tourniquet from 8 subjects who had been lying supine for 15 minutes and again after sitting for 5 minutes. In the second study, to test the effect of venous compression, blood was taken from 11 subjects who were seated with a tourniquet applied for 5 minutes and then immediately again from the other arm without a tourniquet. In the third study, to test the combined effect of both factors, 15 subjects had blood taken without a tourniquet while supine for 15 minutes and then after being seated for 5 minutes with a tourniquet applied. Serum T3 and T4 were measured by specific radioimmunoassays ${ }^{4}$ on all samples in the same assay. Intrassay variation for both $\mathrm{T} 3$ and $\mathrm{T} 4$ was less than $5 \%$. Free thyroxine index (FTI) was calculated as the product of T4 and T3 resin uptake (T3 RU) measured by a kit method (NML). Results were analysed with the paired Wilcoxon test for matched samples.

The effect of the procedures are illustrated in the figure.
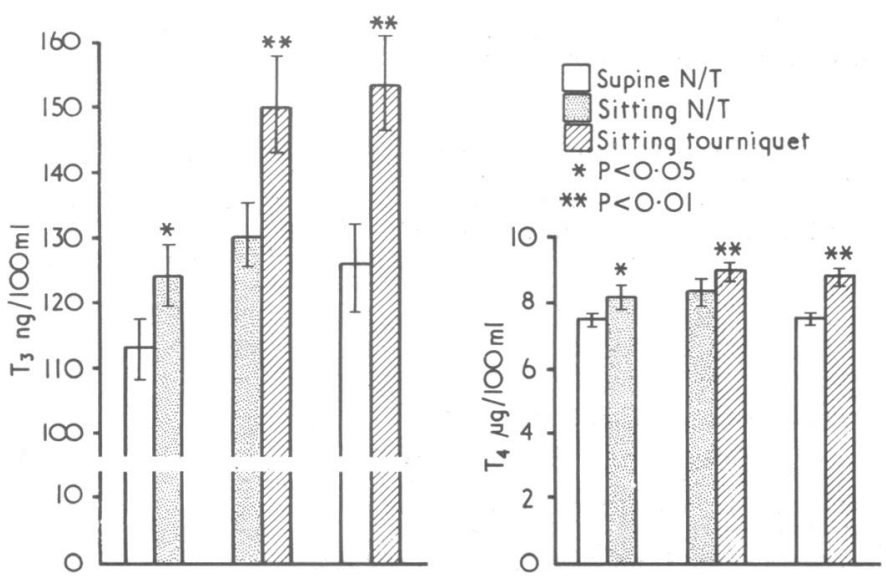

Effect of haemoconcentration of serum levels of triiodothyrine and thyroxine.

(1) Postural change caused a mean $( \pm S E M)$ increase in serum T3 from $113+4.3$ to $124+4 \cdot 7 \mathrm{ng} / 100 \mathrm{ml}$, and in serum T4 from $7 \cdot 4 \pm 0.2$ to $8 \cdot 1+0 \cdot 3$ $\mu \mathrm{g} / 100 \mathrm{ml}$. This represents a mean percentage rise in T3 of $9 \cdot 7 \%$ (range $0-29 \%$ ) and in T4 of $8 \%(0-37 \%)$. There was a significant decrease in mean T3 RU from $101 \pm 2.9 \%$ to $95 \pm 2.4 \%(P<0.05)$. The change in FTI from 7.5 to $7 \cdot 8$ was not significant $P>0 \cdot 10$ )

(2) Tourniquet compression increased the mean serum $\mathrm{T} 3$ from $130 \pm 5.0$ to $150 \pm 7 \cdot 4 \mathrm{ng} / 100 \mathrm{ml}$ and serum $\mathrm{T} 4$ from $8.3 \pm 0.4$ to $8.9 \pm 0.3 \mu \mathrm{g} / 100 \mathrm{ml}$. This represents a mean percentage change of $15 \%$ (range $0-31 \%$ ) in serum T3 and 7\% (range $0-16 \%$ ) in serum T4. There was a significant decrease in T3 RU from a mean of $97 \pm 2.3 \%$ to $91 \pm 3.0 \%$ $(P<0.01)$ but FTI was unchanged.

(3) The combined effect of venous compression and postural change increased the mean serum T3 from $126 \pm 7 \cdot 6$ to $153 \pm 8 \cdot 4 \mathrm{ng} / 100 \mathrm{ml}$ and mean serum $\mathrm{T} 4$; from $7 \cdot 4 \pm 0.2$ to $8 \cdot 7 \pm 0.3 \mu \mathrm{g} / 100 \mathrm{ml}$. This represents a mean percentage increase of $21 \%$ (range $0-60 \%$ ) in serum T3 and $18 \%$ (range $0-44 \%$ ) in serum T4. There was a significant decrease in T3 RU from a mean of $100 \pm 1.9 \%$ to $91 \pm 2.2 \%(P<0.01)$. The increase in FTI from 7.5 to 7.9 was not significant $(P>0.01)$.

\section{Discussion}

This study has shown that alterations in posture and venous compression significantly increase the serum concentrations of $T 3$ and $T 4$. The significant decrease in T3 RU but insienificant change in FTI indicates that the increase in total $\mathrm{T} 3$ and $\mathrm{T} 4$ is due to an increase in thyroid hormone-binding protein proportional to the increases in T3 and T4. This emphasises the need for a careful and standardised technique of drawing blood for thyroid hormone estimations, particularly when serial changes are being interpreted. These effects are also important when establishing normal laboratory ranges for T3 and T4 and when comparing outpatient and inpatient populations. The effects described of posture and venous compression may similarly influence the plasma concentrations of other protein-bound hormones.
This work is supported by grants from the National Health and Medical Research Council of Australia. Requests for reprints should be addressed to Dr S J Judd Garvan Institute of Medical Research, St Vincent's Hospital, Sydney, N S W, Australia. We gratefully acknowledge the help of Professor L Lazarus for his encouragement and advice; Ms C Batley for thyroid hormone estimations; and Ms J Chalmers for typing the manuscript. Dr E Kraegen helped us with the statistical analysis.

1 Fawcett, J K, and Wynn, V, fournal of Clinical Pathology, 1960, 13, 304. 2 Gerbrandy J, van Leeuwen A M, Hellendoorn, H B A, and de Vries, L A, Clinical Science, 1960, 19, 181.

${ }^{3}$ Lewitus, Z, and Steinitz, K, Clinica Chimica Acta, 1963, 8, 629.

4 Burke, C W, and Eastman, C J, British Medical Bulletin, 1974, 30, 93.

Garvan Institute of Medical Research, St. Vincent's Hospital, Sydney, N S W 2010.

S J JUDD, MB, FRACP, clinical fellow in endocrinology

J N CARTER, MB, FRACP, clinical fellow in endocrinology

J M CORCORAN, BSC, scientific officer

The finding of more than one malignancy of different origin in a patient is not uncommon at necropsy, though usually only one malignancy has contributed to death, the others being incidental findings. A patient who develops and is treated for five separate malignancies is likely to be unique.

\section{Case History}

A 51-year-old woman was admitted for the investigation of painless haematuria and found to have a $6 \mathrm{~cm}$ tumour at the right bladder base causing fixation to the pelvic side wall. Biopsy showed a poorly differentiated transitional cell carcinoma with muscular invasion. Thirteen years previously she had had a bilateral ovarian cystectomy for treatment of a torsion of a left ovarian cyst, shown histologically to be a moderately differentiated papillary adenocarcinoma. The capsule was intact and the right ovary normal. One year later she developed intermenstrual bleeding and curettage suggested the presence of a uterine tumour. The hysterectomy specimen showed a localised adenocarcinoma with deep invasion of the myometrium at the fundus; moreover, the cervix also showed areas of carcinoma in situ. After her operation she underwent a radical course of pelvic irradiation. Seven years later a hemicolectomy was performed for the removal of an adenocarcinoma of her caecum. The neoplasm had invaded all layers of the intestinal wall but no lymph nodes in the specimen were affected, nor was there evidence of abdominal or pelvic metastases.

The patient had remained well for five years before presenting with haematuria. Three months later, after a palliative course of radiation, cystoscopy showed no evidence of residual growth and she has remained symptom free for a further eighteen months.

\section{Discussion}

A search of published work has shown one other patient with five separate malignancies, ${ }^{1}$ affecting the breast, colon, skin, ureter, and body of the uterus. My patient was fortunate that her tumours presented at an early stage and were readily curable. After surgical removal of early localised ovarian, uterine, cervical, and colonic carcinomas the prognosis is known to be good.

Unsuspected preinvasive cervical carcinoma is found in $4 \%$ of hysterectomy specimens, while a review of all cases of ovarian malignancy registered in the Cambridge area during 1960-74 showed six cases of concurrent cervical neoplasm, of which four were in situ. $\mathrm{Cook}^{2}$ found that women who have a primary ovarian carcinoma have a significantly increased risk of developing endometrial cancer $(P>0.05)$, though his data provide no evidence of any relation between ovarian or uterine malignancy with colonic, bladder, or cervical carcinoma. Nevertheless, $3 \%$ of Polk's $\mathbf{s}^{3}$ cases of colonic carcinoma had a history of cancer elsewhere in the body and according to him a 